\title{
Cytological Result of In Situ Ductal Carcinoma in Nipple Discharge: A Rare Diagnosis
}

José Cândido Caldeira Xavier-Júnior ${ }^{1}$, Rafael Bispo Paschoalini ${ }^{1}$, Rafael André Gonçalves Rosa ${ }^{2}$, Vinicius Capistrano Ferreira ${ }^{3}$, Mariangela Esther Alencar Marques $^{1}$, José Ricardo Paciência Rodrigues ${ }^{2}$, Sonia Marta Moriguichi ${ }^{3}$ and Rozany Mucha Dufloth ${ }^{1}$

${ }^{1}$ Department of Pathology, UNESP- Universidade Estadual Paulista, Brazil

${ }^{2}$ Department of Obstetrics and Gynecology, UNESP- Universidade Estadual Paulista, Brazil

${ }^{3}$ Departament of Diagnostic Imaging, UNESP - Universidade Estadual Paulista, Brazil

"Corresponding author: José Cândido Caldeira Xavier Júnior, Resident of Pathology, Department of Pathology, Botucatu Medical School, Paulista State University (UNESP), Rubião Júnior s/n, 18618-970. Botucatu - SP, Brazil, Tel: + 55 (14) 3811-6238; Fax: + 55 (14) 38152348; E-mail: josecandidojr@yahoo.com.br

Rec date: Jul 25, 2014, Acc date: Oct 16, 2014, Pub date: Oct 18, 2014

Copyright: (c) 2014 Xavier-Júnior JCC, et al. This is an open-access article distributed under the terms of the Creative Commons Attribution License, which permits unrestricted use, distribution, and reproduction in any medium, provided the original author and source are credited.

\begin{abstract}
Background: More than half of women present nipple discharge during reproductive age.

Case: This case is about a 36 years old woman with unilateral spontaneous hyaline nipple discharge associated with breast pain. The study of scintimammography was compatible with multifocal proliferative lesion in situ. It was performed cytological smear of nipple discharge.

It was paucicellular smear represented by cluster of ductal cells in three-dimensional design with hyperchromatic nuclei in the presence of myoepithelial cells. Red cells and signs of necrosis were not observed. The diagnosis of in situ ductal carcinoma was confirmed in biopsy and mastectomy specimen through the expression of calponin in myoepithelial cells at immunohistochemistry. It is known that the cytological examination of nipple discharge has low sensitivity and specificity. However, it is an easy and inexpensive procedure. Suspicious or positive results, may be important for guidance workup of patients in order to perform earlier diagnosis of malignancy.
\end{abstract}

Conclusion: this case demonstrates that in situ ductal carcinoma can be characterized by positive nipple discharge, and cytology sample is an important tool for the diagnosis of suspicion of malignancy and further diagnostic investigation.

Keywords: Breast cytology; Breast pathology; Cytology; Cytomorphology

\section{Background}

More than half of women present nipple discharge during reproductive age, one of the most common complaints of mastology offices [1-4]. Cytological analysis of nipple discharge does not allow differentiation between papilloma and papillary carcinoma. However, other carcinomas may be present as cohesive clusters of ductal cells with cytological features of malignancy [3], including the ones that can mimic papillary architecture, as in that present case. This is in situ ductal carcinoma with histological evidence presented as a positive nipple discharge characterized by paucicelular smear arranged in cohesive groups with hyperchromatic and overlapping nuclei delineating papillae. It could illustrate how important the cytological analyses of nipple discharge might be in patients following-up through the malignant diagnosis.

\section{Case Report}

Female, 36 years old, with unilateral spontaneous hyaline nipple discharge associated with breast pain. Gynecological history of menarche at 13 years, primiparity at 19 years, two pregnancies with two years of lactation each one. Physical examination showed that breasts are medium and symmetrical, without retraction or bulging. The right breast showed medial thickening in medial quadrants sizing approximately $2 \mathrm{~cm}$, with hyaline secretion when pressing. Left mamma was unchanged. Armpits and clavicle fosse were free.

The study of scintimammography was performed in order to evaluate the tumor aggressiveness, location and the probability of response to chemotherapy. It showed diffuse and heterogeneous concentration of radiopharmaceutical with multiple focal areas in the right breast revealing that it was a condition compatible with multifocal in situ proliferative lesion [5]. In the left breast it was noted homogeneous distribution of the radiopharmaceutical. No anomalous concentration of the radiopharmaceutical was detected in projection of armpits (Figure 1).

Cytological smear of nipple discharge was performed. The slides were stained with Giemsa. It was paucicellular smear represented by clusters of cells delineating papillae in the presence of myoepithelial cells. The cells were round or oval, showing overlapping and hyperchromatic nuclei giving appearance of three-dimensionality. Red cells and signs of necrosis were not observed. In this context, it was considered malignant [6] (Figure 2a-2c). 
Citation: Xavier-Júnior JCC, Paschoalini RB, Rosa RAG, Ferreira VC, Marques MEA, et al. (2014) Cytological Result of In Situ Ductal Carcinoma in Nipple Discharge: A Rare Diagnosis . J Cytol Histol 5: 284. doi:10.4172/2157-7099.1000284

Page 2 of 4
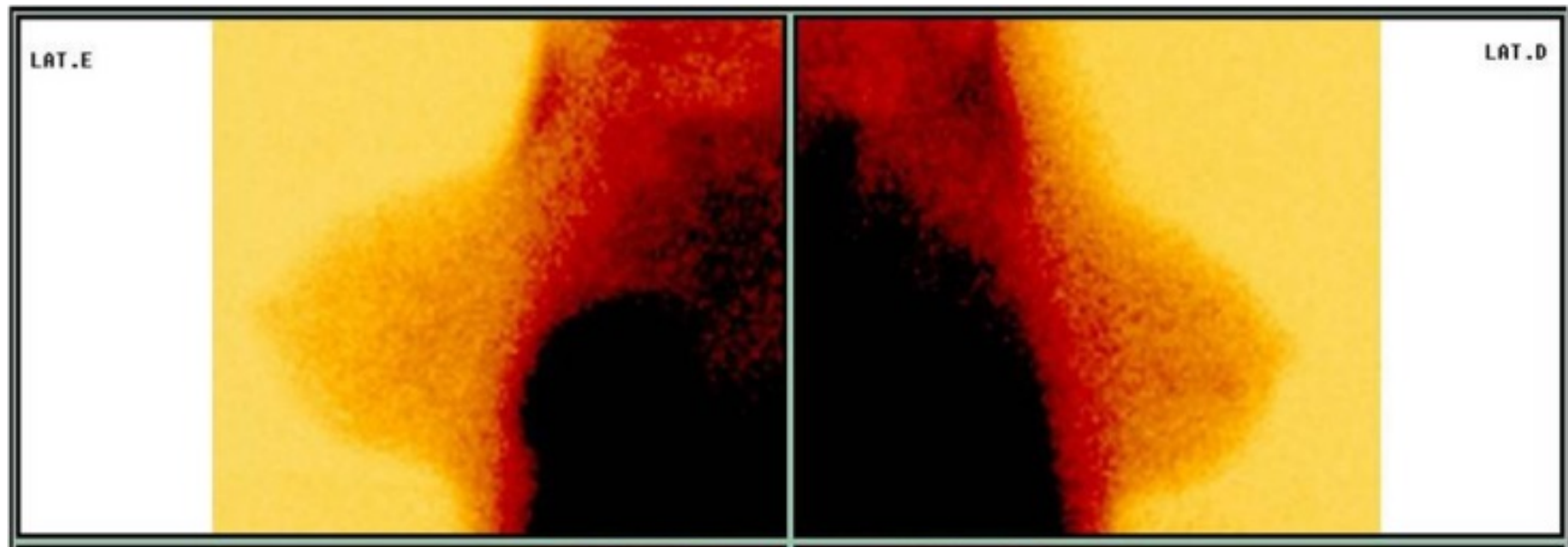

OPE

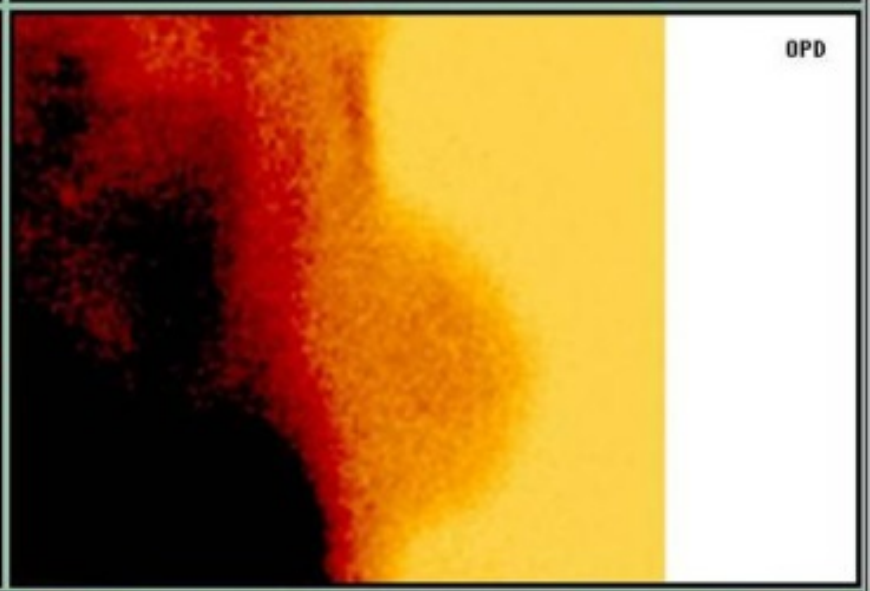

\section{ANIERIOR}

ANTERIOR C/ $200 \mathrm{M}$

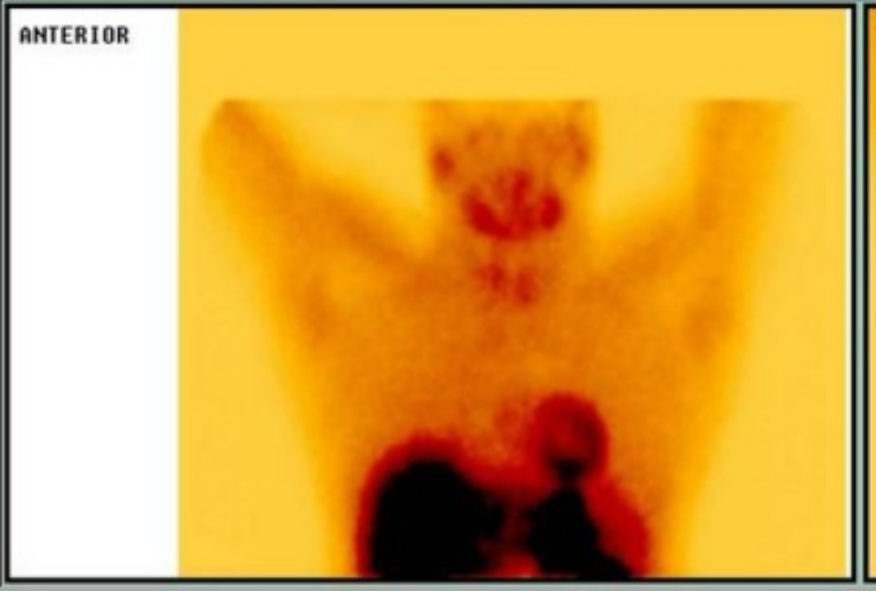

Figure 1: Scintimammography demonstrating diffuse and heterogeneous concentration of radiopharmaceutical with multiple focal areas in the right breast which is compatible with multifocal proliferative lesion in situ.

The histological analysis of core biopsy identified in situ ductal carcinoma with cribriform and solid areas, revealing positivity for estrogen (100\%) and progesterone receptor $(70 \%)$, negative for oncogenic Her-2 protein. The estimated proliferation cellular index (Ki67) was $10 \%$ at immunohistochemistry.
The patient underwent a mastectomy. In the macroscopic examination of the breast we observed a whitish, firm with starring appearance single nodule measuring approximately $1.1 \times 1 \mathrm{~cm}$. The whole tumor was subjected to histological examination confirmed the diagnosis of in situ ductal carcinoma presented solid, papillary and cribriform areas (Figures 3 and 4). The calponin stain at immunohistochemistry analyses looking for myoepithelial cells was positive, confirming the diagnosis of in situ carcinoma. 
Citation: Xavier-Júnior JCC, Paschoalini RB, Rosa RAG, Ferreira VC, Marques MEA, et al. (2014) Cytological Result of In Situ Ductal Carcinoma in Nipple Discharge: A Rare Diagnosis . J Cytol Histol 5: 284. doi:10.4172/2157-7099.1000284

Page 3 of 4

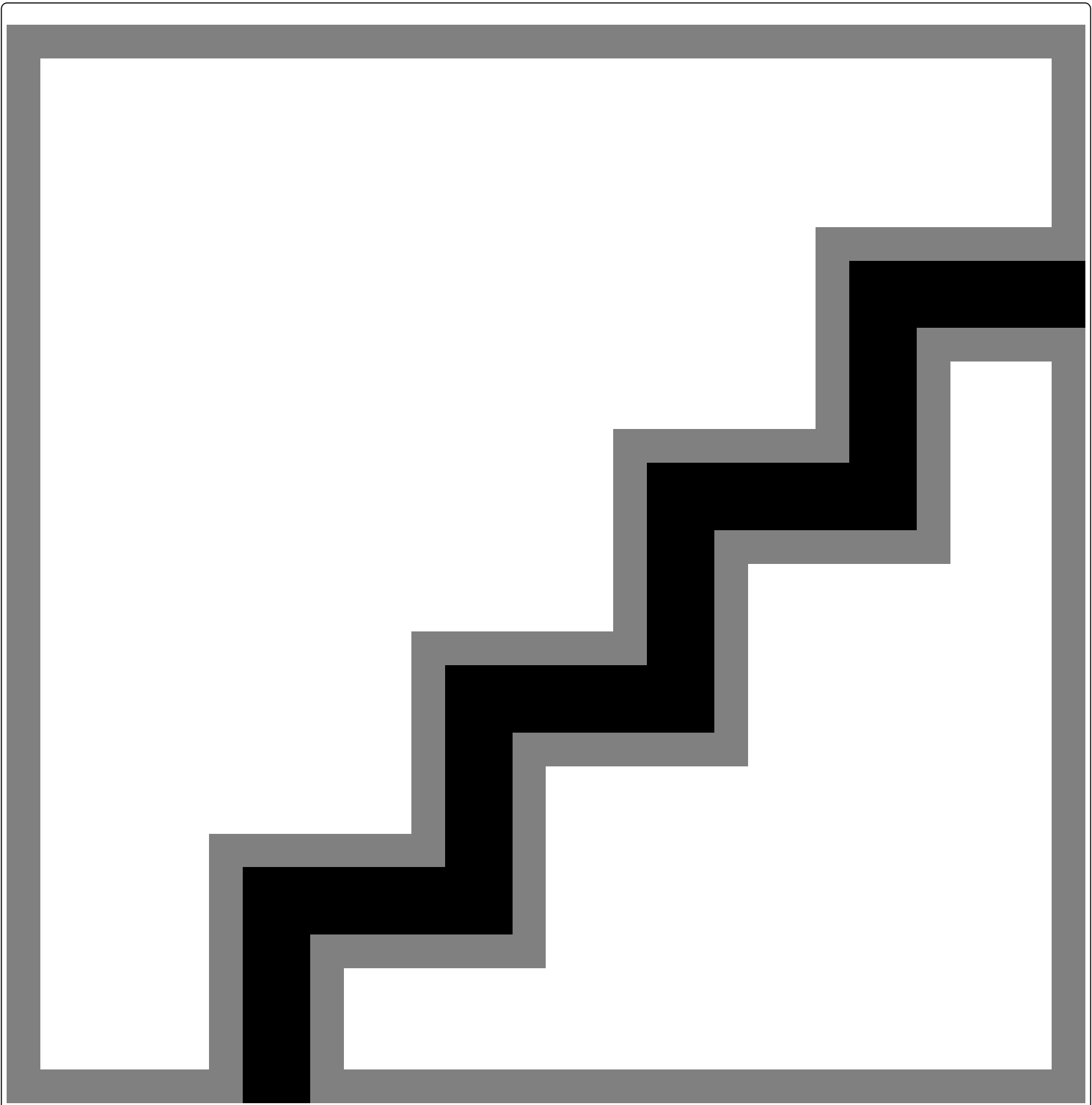

Figure 2: (a-c) cluster of ductal cells in three-dimensional design with hyperchromatic nuclei. At the edges the myoepithelial cell might be identified. The background is clear.

\section{Discussion}

Nipple discharge is considered abnormal when it comes to selfdischarge, non-pregnant / postpartum, usually unilateral, independent of macroscopic feature (serous, bloody, crystalline sanguinolent). Most cases of nipple discharge are consequential to papillomas or ductal ectasia, however, all patients should undergo clinical / imaging examination to exclude maligninancies [1-4].

It is known that the cytological examination of nipple discharge has low sensitivity and specificity for malignances diagnosis [2,7]. However, it is an easy and inexpensive procedure. Suspicious or positive results, may be important for guidance workup of patients in order to perform earlier diagnosis of malignancy (2-3). Since the 
Citation: Xavier-Júnior JCC, Paschoalini RB, Rosa RAG, Ferreira VC, Marques MEA, et al. (2014) Cytological Result of In Situ Ductal

Page 4 of 4

nipple discharge can be achieved is a simple procedure, it can be done by healthy professionals in general practice in the early approach. In case of positivity or suspicious result it could be the first method to reference patient straightforward to a specialized service, saving time and money.

In this context, it is necessary to disseminate the cytology pattern of nipple discharge especially for malignancies in situ, since there is no palpable mass the submission of discharge is an early signal of disease $[7,8]$ that deserves expert evaluation. Cytopathology might watch out those specimen even though the smear is paucicellular.

In situ ductal carcinoma is a premalignant lesion consisting of neoplastic proliferation of epithelial cells contained within the lumen of the breast duct. Microscopically, the biggest difference between DCIS and invasive ductal carcinoma is the presence of myoepithelial cells and intact basal membrane $[9,10]$. In that context, immunohistochemistry stain is helpful to emphasize the presence of myoepithelial cell as in this case.

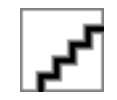

Figure 3: demonstrating high grade in situ ductal carcinoma with cribriform pattern.

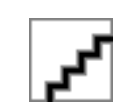

Figure 4: Immunohistochemistry- calponina stain was positive highlighting the myoepithelial cells and corroborating the diagnosis of in situ ductal carcinoma.

In conclusion, this case demonstrates that in situ ductal carcinoma can be characterized by positive nipple discharge, and cytology sample is an important tool for the diagnosis of suspicion of malignancy and further diagnostic investigation. In a paucicellular smear showing cohesive clusters with hyperchromatic nuclei and three-dimensional aspect the suspicion of "in situ" ductal carcinoma should be considered. Future studies are necessary for defining criteria that could differentiate cytological discharge from in situ papillary ductal carcinoma of a papillary lesion.

\section{References}

1. Onstad M, Stuckey A (2013) Benign breast disorders. Obstet Gynecol Clin North Am 40: 459-473.

2. Hussain AN, Policarpio C, Vincent MT (2006) Evaluating nipple discharge. Obstet Gynecol Surv 61: 278-283.

3. Kooistra BW, Wauters C, van de Ven S, Strobbe L (2009) The diagnostic value of nipple discharge cytology in 618 consecutive patients. Eur J Surg Oncol 35: 573-577.

4. Cowell CF, Weigelt B, Sakr RA, Ng CK, Hicks J, et al. (2013) Progression from ductal carcinoma in situ to invasive breast cancer: revisited. Mol Oncol 7: 859-869.

5. Parthasarathy V, Rathnam U (2012) Nipple discharge: an early warning sign of breast cancer. Int J Prev Med 3: 810-814.

6. Das DK, Al-Ayadhy B, Ajrawi MT, Shaheen AA, Sheikh ZA, et al. (2001) Cytodiagnosis of nipple discharge: a study of 602 samples from 484 cases. Diagn Cytopathol 25: 25-37.

7. Lee WY (2003) Cytology of abnormal nipple discharge: a cytohistological correlation. Cytopathology 14: 19-26.

8. Masood S, Khalbuss WE (2005) Nipple fluid cytology. Clin Lab Med 25: 787-794, vii-viii.

9. Moriguchi SM, DE Luca LA, Griva BL, Koga KH, DA Silva ET, et al. (2010) Accuracy of (99m)Tc-sestamibi scintimammography for breast cancer diagnosis. Exp Ther Med 1: 205-209.

10. Das DK, Al-Ayadhy B, Ajrawi MT, Shaheen AA, Sheikh ZA, et al. (2001) Cytodiagnosis of nipple discharge: a study of 602 samples from 484 cases. Diagn Cytopathol 25: 25-37. 